\title{
A experimentação como instrumento para o ensino de titulometria para uma turma de graduandos em licenciatura em Química
}

Experimentation as an instrument for teaching a class of students with degree in licentiate in chemistry

\author{
P. W. P. Gomes ${ }^{1 *}$; A. J. B. Muribeca ${ }^{2}$ J. M. Campos 2 ; A. P. A. da Costa ${ }^{2}$; B. V. \\ Malato $^{2}$; D. S. C. Silva ${ }^{2}$; R. F. de Souza ${ }^{2}$ \\ ${ }^{1}$ Programa de Pós-Graduação em Química, Universidade Federal do Pará, 66075-970 Belém, Pará, Brasil. \\ ${ }^{2}$ Departamento de Ciências Naturais/Grupo de Pesquisa em Química, Ensino de Química e Meio Ambiente, Campus \\ XIX/Salvaterra, Universidade do Estado do Pará, 68860-000, Salvaterra, Pará, Brasil \\ *wenderufpa@hotmail.com \\ (Recebido em 02 de abril de 2016; aceito em 16 abril de 2016)
}

\begin{abstract}
O presente trabalho teve por finalidade utilizar materiais alternativos e de baixo custo como instrumentos para utilizar a experimentação de forma a propiciar uma aprendizagem significativa e contextualizada no ensino de Química. A atividade foi desenvolvida com alunos do primeiro semestre do curso de Licenciatura em Ciências Naturais - Habilitação em Química do Campus XIX da Universidade do Estado do Pará, localizado no município de Salvaterra, Pará (Ilha de Marajó). A estrutura alternativa para a realização dos ensaios titulométricos foi confeccionada a partir da reutilização de materiais encontrados no dia-a-dia e pela compra de materiais descartáveis no comércio local. Foram realizados cinco ensaios titulométricos com dispersões comuns do dia-dia dos alunos: suco de frutas, extrato de tomate, mel, leite de magnésia e leite integral. Para a realização das práticas e discussão sobre os fenômenos observados, a turma de 30 alunos foi dividida em grupos. Posteriormente, os alunos elaboraram um texto dissertativo, com o propósito de validação da aprendizagem com a utilização da ferramenta alternativa. Os dados obtidos permitiram diagnosticar que todos os indivíduos envolvidos na atividade aprovaram o uso da ferramenta enquanto um recurso pedagógico para o ensino de química. Acredita-se que a utilização da experimentação a partir de materiais alternativos potencializa sua eficácia nas relações de ensino e aprendizagem em Química.

Palavras-chave: Aprendizagem significativa, Ensino de química, Materiais alternativos
\end{abstract}

This work had as purpose to use alternative materials and low-cost as tools to use experimentation in order to provide a meaningful and contextualized learning in teaching chemistry. The activity was developed with undergraduate students in the first semester of the Natural Sciences course - Habilitation in Chemistry of the 19th Campus of the University Pará State, located in the municipality of Salvaterra, Pará (Marajó Island). The alternative structure to perform the titrimetric tests was made from the reuse of materials encountered in daily and for the buy of disposable materials in local market. Five tests were carried out titrimetrics with usual dispersions in daily life of students: fruit juice, tomato paste, honey, milk of magnesia and whole milk. To perform the practice and discuss about phenomena observed, the class of 30 students was divided into groups. Later, the students drafted an argumentative text, with the purpose of evaluating learning validation using the alternative tool. The data obtained allowed to diagnose that all individuals involved in the activity approved the use of the tool as a teaching resource for the teaching of chemistry. It is believed that the use of experimentation from alternative materials increase your effectiveness in teaching and learning in chemistry. Keywords: Meaningful learning, Chemistry teaching, Alternative materials 


\section{INTRODUÇÃO}

A Química é o ramo da Ciência que estuda a matéria, sua composição, transformação e as condições envolvidas nesse processo. É importantíssima para a elucidação dos fenômenos da natureza, pois é um instrumento bastante importante para investigação, produção de bens, desenvolvimento socioeconômico e colaborador na atuação dos cidadãos [1]. Não obstante, a conjuntura atual que as escolas - em sua particularidade as públicas - têm refletido sobre o ensino de química é alarmante. Estudar química nesse contexto tem se tornado sinonímia de "aulas cansativas", "memorização de fórmulas" e "leis inquestionáveis e imutáveis", o que implica em inferiores níveis cognitivos [2].

Uma vez que isso acontece é emergente a busca de novos métodos e estratégias que revertam esse quadro. Os grandes e mais renomados estudiosos da área da educação $[3,4,5]$ encontraram na experimentação uma perspectiva positiva. Ela se justifica porque está ligada à estrutura da Ciência, assim como à reformulação conceitual dos alunos [6]. Essas características são geralmente defendidas entre a maioria dos professores que acreditam que a experimentação é uma ferramenta eficaz no que tange às relações de ensino e aprendizagem. Pois, contempla a "íntima" e peculiar interação do aluno com objeto estudado, quer isso se reflita na manipulação e/ou visualização [2].

Para Baratieri et al [7] as atividades experimentais podem assumir um caráter construtivista porque conduzem os alunos a buscar e confrontar informações, reconstruindo ideias e maneiras de explicar problemas. Tal realidade também é enfatizada por Galiazzi et al [8], onde destaca que o uso da experimentação é essencial para uma boa aprendizagem, tendo em pauta, diminuir as lacunas entre o teórico e o prático, porém é pouco utilizada pelos docentes nas aulas das diversas ciências, mesmo estando presente no planejamento do professor acaba sendo inutilizada.

Dessa forma, é perceptível através das investigações que as aulas experimentais não são utilizadas pelos docentes das ciências [9,10], com destaque para os que atuam nas escolas brasileiras, estes que se limitam apenas a aulas teóricas em sala de aula [8]. Ao estudar esse comportamento Salvadego et al [11] justificam-nas pela ausência de práticas recém preparadas, falta de tempo para prepará-las devido a excessiva carga horária que lhes são atribuídas, insuficiência de recursos para aquisição de matérias, espaço apropriado para realização da experimentação em química.

Segundo Borges [10], a principal deficiência está no excessivo número de discentes por classe, deficiência na formação continuada do professor, atualização de bibliografias, tempo de aula insuficiente para aplicação da experimentação, ausência de um laboratório. Salvadego et al [11] possuem importante papel quando destacam que, nas ínfimas eventualidades de existência de um laboratório, a sua utilização se restringe ao fato dos alunos apresentarem comportamento inadequado nesse ambiente, por conversarem demais, mexerem indevidamente nos materiais e equipamentos e ainda por insuficiências do professor

Fazendo uma síntese das discussões apresentadas até aqui, os autores citados até então são transparentes em apontar que há uma significativa resistência dos docentes em utilizar práticas experimentais, como um instrumento auxiliador do ensino das Ciências; esses profissionais se justificam singularmente na deficiência ou ausência de espaço adequado, o qual impossibilita o uso da experimentação.

Savadego et al [11] afirmam que uma aula experimental, seja ela com manipulação do material pelo aluno ou demonstrativa, não está associada a um aparato experimental sofisticado, mas à sua organização, discussão e análise, que possibilitam interpretar os fenômenos químicos e a troca de informações entre o grupo que participa da aula. Desta forma, buscou-se desenvolver uma atividade experimental que isentasse a necessidade de ser realizada exclusivamente nas dependências de um laboratório de química. Para tanto, fez-se uso de materiais alternativos que substituíram os equipamentos sofisticados dos laboratórios. 


\section{MATERIAL E MÉTODOS}

O sujeito participante da pesquisa foi uma turma composta por 30 alunos do primeiro semestre do curso de Licenciatura em Ciências Naturais com habilitação em Química da Universidade do Estado do Pará/ Campus XIX, município de Salvaterra, localizado na Ilha do Marajó, Estado do Pará.

Os participantes foram divididos em grupos, onde foi possível realizar a discussão dos fenômenos observados durante o desenvolvimento da atividade experimental. A atividade consistiu em uma revisão preliminar acerca do que a química compreende e sua importância para a sociedade e ambiente; também foi feita uma abordagem mais específica acerca do tema em questão, como conceitos e definições sobre dispersão com enfoque nas soluções aquosas e nas titulações ácido-base.

Para a realização da prática experimental, os participantes trouxeram material de suas próprias residências para ser analisado. Os materiais foram: suco de frutas, extrato de tomate, mel, leite de magnésia e leite integral. A viabilização dos procedimentos dos ensaios de titulação foi intermediada por uma estrutura confeccionada a partir da reutilização e compra de materiais alternativos e de baixo custo encontrados no cotidiano.

$\mathrm{O}$ anteparo consistiu de uma haste de madeira $(30 \mathrm{~cm})$ fixada em uma base, também do mesmo material, com formato retangular $(10 \mathrm{~cm} \times 8 \mathrm{~cm})$. Na haste, uma seringa graduada (20 $\mathrm{mL}$ ) sem o êmbolo foi fixada com auxílio de um pedaço de arame de cobre "recozido", e em sua extremidade inferior fixou-se um pedaço de mangueira (utilizada para infusão intravenosa) conjuntamente com uma "pinça rolete" (utilizada para aplicação de soros fisiológicos) para dosagem de volume. Na base, uma lâmpada incandescente sem filamento substituindo o "erlenmeyer" complementou o aparato. A escolha desta última, foi principalmente por ser transparente e de material inerte (vidro), facilitando a percepção do ponto de viragem do indicador (que ocorre em média com pH próximo de 8,3, cor rósea) como mostra a figura 1.

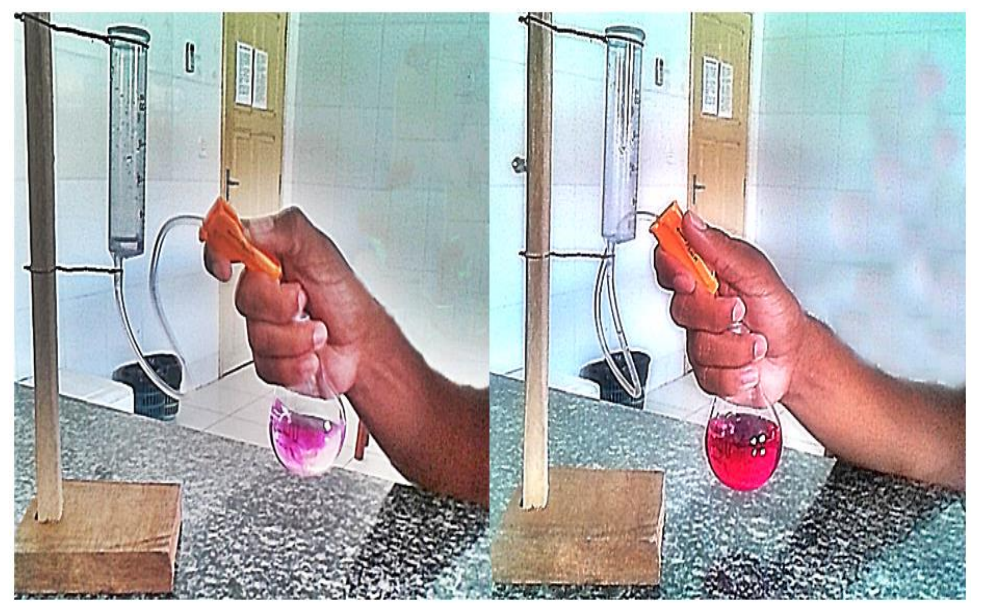

Figura 1. Instrumento utilizado para realização dos ensaios titulométricos.

As soluções titulantes foram preparadas em diferentes concentrações molares. Para titulação de soluções ácidas utilizou-se solução de hidróxido de sódio $0,1 \mathrm{~mol} / \mathrm{L}$, preparada a partir de $\mathrm{NaOH} 70 \% \mathrm{~m} / \mathrm{m}$, conhecida comercialmente como soda cáustica; para titulação de soluções básicas utilizou-se solução de ácido acético $0,1 \mathrm{~mol} / \mathrm{L}$, obtida a partir de vinagre comercial $4 \%$ $\mathrm{m} / \mathrm{v}$; como indicador foi utilizada solução alcoólica de fenolftaleína $1 \% \mathrm{~m} / \mathrm{v}$.

Dados comparativos garantiram que a seringa utilizada em substituição da bureta permitisse uma reprodução bastante fiel daquelas realizadas pela própria aparelhagem de laboratórios.

Ao término da atividade, os alunos escreveram um texto dissertativo pautando as relevâncias que a utilização da experimentação, enquanto ferramenta metodológica no ensino de Química, representam nas relações de ensino-aprendizagem. Neste sentido, buscou-se uma análise dos textos elaborados pelos alunos, com mensagens implícitas contidas nas entrelinhas e não nas estruturas literais evidentes. 
Bakhtin [12] aponta que a unidade de comunicação é composta por enunciados informais, mais ou menos estáveis, ou seja, por gênero do discurso, pertencente a uma determinada atividade humana. Assim, o texto passa a ser um produto natural da sincera posição humana a respeito de algo, que constitui a esfera essencial em busca da boa aprendizagem. Desta maneira, é plausível e cabível afirmar o quão a experimentação configurou-se importante para as relações que sustentam as condições efetivas de aprendizagem significativa, além de especular um diagnóstico quanto ao uso ou não de práticas experimentais nas aulas de química.

\section{RESULTADOS E DISCUSSÃO}

Diante dos resultados obtidos foi possível verificar que os participantes (futuros docentes da região) consideram a experimentação como uma alternativa para melhorar o ensino e a aprendizagem na disciplina química e seus eixos transversais. Assim, acredita-se que ao se utilizar o instrumento confeccionado a partir de materiais alternativos e cotidianos, não proporcionando riscos durante o manuseio, é uma prática que pode ser adotada em outros níveis de ensino.

Através da utilização de materiais acessíveis, os participantes presenciaram o passo a passo da química experimental e tiveram a oportunidade de discutir sobre a química aplicada no dia-adia. Araújo [13] destaca em seu trabalho que o desenvolvimento de práticas experimentais com materiais e reagentes de baixo custo - e de fácil aquisição - é um aspecto importante na formação docente, pois passa a ser relevante na busca por adoção de estratégias de desenvolvimento de experimentos em sala de aula.

As repetições dos ensaios titulométricos permitiram a aquisição de habilidades práticas e maturidade na interpretação dos fenômenos observados. O que remete à ideia e comprovação de que as atividades experimentais estabelecem uma interatividade direta com o objeto estudado, resultando em um aprendizado significativo.

Em seus depoimentos, os participantes enfatizaram que a utilização de materiais de baixo custo e acessíveis foi um fator bastante colaborador para a eficácia da ferramenta enquanto recurso pedagógico no ensino de química, visto que a maioria das escolas da região não possui laboratório de química, como se observa nas falas dos alunos A1 e A2 transcritas na íntegra:

[A1] “...a gente nem precisou de um laboratório, pois através de materiais que teriam como destino a lata de lixo, conseguimos aproveitar ao máximo e transformar em um instrumento facilitador no ensino de fenômenos químicos, visto na maioria das vezes apenas de forma teórica e imaginaria”.

[A2] “... a partir de agora irei olhar com outros olhos para fenômenos simples da minha rotina, pois através da prática de titulação percebi que a química está presente constantemente em nosso dia-a-dia e devido fixarmos apenas na teoria acabamos por perder a prática fenomenal que pode ser demonstrada e estudada através de materiais recicláveis acessíveis e de baixo custo".

Os participantes convenceram-se que há uma necessidade emergencial de mudar o quadro em que o ensino de química atualmente se encontra e apontaram o uso da experimentação como uma alternativa metodológica capaz de unificar a teoria e a prática. Muitos dos participantes tiveram oportunidades de aprender conceitos sobre titulação de soluções aquosas de uma maneira mais acessível e dinâmica. Como se evidencia nos relatos dos alunos A3 e A4, que transpareceram a abstração que esse conteúdo antes representava.

[A3] “...se já estudei titulação, não lembro mais, pois foi uma aprendizagem motora e sem novidades metodológicas, restrita somente ao quadro magnético..." 
[A4] "eu nunca tinha feito isso, só aprendi no cursinho, mas foi só cálculo mesmo, decorando fórmulas, porém agora irei ter uma nova perspectiva quando for professor de química, buscando sempre algo novo e que chame atenção dos alunos..."

Para Souza et al [14], as aulas práticas demonstrativas, como o show da química, podem dar um caráter de espetáculo ou de magia para os alunos, mas também podem ser úteis na perspectiva de divulgação do conhecimento químico; pois são recursos alternativos que podem e devem ser utilizados, desde que adequadamente.

Foi possível perceber que a estratégia de ensino utilizada foi inovadora naquele contexto e de fundamental importância no processo de ensino-aprendizagem da química e na formação de futuros professores dessa área. Freitas Filho et al [15] afirmam que os materiais alternativos se constituíram em uma ferramenta facilitadora para o ensino de química, especificamente ao ensino de titulação, pois um dos agravantes para introdução de atividades experimentais em química é o custo de materiais e de instrumentos, além da não formação específica dos professores.

Os participantes apontam que um roteiro experimental é indispensável, contudo não pode ser encarado como um manual que deva prender o aluno a seguir à risca todos os passos, pois os erros e acertos já seriam previstos pelo professor. Mas que o roteiro deva apenas nortear o aluno quanto à manipulação dos equipamentos e reagentes.

Em muitos dos depoimentos obtidos, vale destacar a seguinte passagem citada por um aluno,

[A5] "os erros também fazem a gente pensar onde errou e tentar ver onde precisa ajeitar".

Esse relato demonstra que na experimentação, os erros também podem levar ao aluno a uma interpretação mais estratégica, ao ponto de até descobrir coisas novas, o que caberia diagnosticar um aprendizado significativo da mesma maneira se fosse um acerto.

Os participantes ainda defendem que é importante cientificar que os materiais alternativos não substituem os equipamentos mais sofisticados e construídos para uma exclusividade experimental analítica, pois isso não irá ilegitimar nem diminuir a expectativa da aula prática. $\mathrm{E}$ por fim, tornar uma teoria mais palpável e com aplicabilidade no cotidiano dos alunos é propiciar a este uma autonomia de investigação, pois uma vez que percebe que a Ciência acaba por ser a interpretação daquilo que está em sua volta, a reprodução e sistematização de futuros outros experimentos são favoráveis de acontecer como escutado durante a socialização dos resultados

[A6] "quando eu chegar em casa vou ver outras coisas para titular".

De acordo com Souza [14] a inclusão da experimentação no ensino de química é justificada pela importância do seu papel investigativo e pedagógico de auxiliar o aluno no entendimento dos fenômenos e na construção dos conceitos. Diante do exposto, restou-se comprovada a inutilização da experimentação pela maioria dos professores em suas aulas, porém a totalidade afirma ter o pleno conhecimento sobre a importância e necessidade de usar esta prática para facilitar a aprendizagem; destacando que é um importante instrumento devido proporcionar um ensino prazeroso para os alunos.

Os dados obtidos neste estudo estão de acordo com os apresentados por Bizzo [16], Krasilchik [17] e Vieira et al [18], onde descrevem que, em geral, o uso de aulas práticas inseridas na disciplina de ciências são recursos pouco utilizados.

Todos os alunos apresentam interesse por aulas práticas, e da mesma forma afirmam que a consideram mais proveitosa, reconhecendo que o fazer ou a simples visualização de uma experiência tornam as aulas mais atrativas, além de contribuírem para a memorização de conceitos [18].

A afirmação de Vieira et al [18] está de acordo com as ideias de Melo et al [19], Santos et al e Nunes et al [21] onde defendem o mesmo pensamento, e destaca-se ainda que estes 
pensamentos coincidem com a realidade vivenciada com a aplicação deste trabalho em sala de aula, no qual se concretizou com os relatos dos graduandos que afirmaram que a metodologia utilizada teve grande eficácia nas duas dimensões de ensino, sendo elas aluno e professor.

As perspectivas desse trabalho foram alcançadas com êxito, onde se chama atenção principalmente para o fato de apropriação da metodologia científica, a curiosidade e a observação da realidade por meio da experimentação realizada neste trabalho, que possibilitou aos atuais discentes - e futuros professores - uma visão de um novo método que poderá ser aprimorado e reaplicado em suas posteriores aulas.

Vale ressaltar que o intuito deste trabalho, ao demonstrar a ideia experimental como ferramenta auxiliadora no ensino-aprendizagem, não foi em nenhuma circunstância sugerir o abandono do livro didático e/ou as aulas expositivas. Mas sim recomendar uma alternativa metodológica na educação, não como um único recurso, mas como uma nova estratégia; diminuindo o estresse acumulativo em aulas teóricas, passando a ser mesclada com aulas práticas, de forma a proporcionar o aprender de forma investigativa, prazerosa e divertida.

\section{CONCLUSÃO}

Acredita-se que a experimentação é bastante promissora no que tange às relações de ensino e aprendizagem, uma vez que esta proporciona ao aluno uma íntima interação com o objeto estudado, tornando-o protagonista da "ação".

O uso de atividades experimentais não requer local específico nem carga horária e pode ser realizada assim que houver a necessidade de fomentar a explicação de conceitos, na resolução de problemas ou mesmo em uma aula exclusiva para a experimentação. Portanto, acredita-se que a experimentação é uma possibilidade de resgatar a essência do Ensino de Química, tendo como foco reestruturá-lo a um caráter investigativo, contextualizado e inovador, isto que a região do desenvolvimento deste estudo apresenta um alto déficit educacional nas ciências naturais desde o ensino fundamental ao médio, buscando desta forma, amenizar este problema que perpassa todos os anos.

É de se constatar que os graduandos, futuros professores, de química demonstraram ter plena consciência da importância da experimentação no processo ensino-aprendizagem e justificam que este recurso pedagógico propicia condições completamente favoráveis para que o discente vivencie as situações diárias, que na maioria das vezes passam despercebidas.

Atribuem ainda que, a experimentação facilita a relação e compreensão com o que está acontecendo no dia-a-dia, levando-o a sintetizar a teoria contextualizada em sala de aula com a prática, passando do abstrato para o concreto.

A escolha por confeccionar estruturas - substituindo aquelas utilizadas em laboratórios - a partir de materiais alternativos e de baixo custo, buscou amenizar as carências enfrentadas por muitas escolas, que é a ausência de laboratório ou estruturas que viabilizem a execução prática de aulas de química; o que resulta em uma gama de resultados positivos nas relações de ensino e aprendizagem.

\section{AGRADECIMENTOS}

A Universidade do Estado do Pará, Campus XIX, por disponibilizar o seu espaço e à turma de graduandos em química que foi o público alvo dessa atividade.

\section{REFERÊNCIAS BIBLIOGRÁFICAS}

1. Wartha EJ, Silva EL, Bejarano NRR. Cotidiano e Contextualização no Ensino de Química. Química Nova na Escola. 2013.; 35(2):84-91.

2. Gomes RS, Macedo SH. Cálculo estequiométrico: o terror nas aulas de Química. Vértices. 2007 jan./dez.; 9(1): 149-160, doi:10.5935/1809-2667.20070010. 
3. Skinner BF. Contingencies of reinforcement. New York: Appleton-Century-Crofts. 1969.

4. Vygotsky LS. A formação social da mente: o desenvolvimento dos processos psicológicos superiores. São Paulo: Martins Fontes. 1984. 224p.

5. Piaget J. Seis estudos de psicologia. Trad. Maria Alice Magalhães D’Amorim e Paulo Sergio Lima Silva. Rio de Janeiro: Forense Universitária, 1995. 156p.

6. Schwahn MCA, Oiagen ER. Objetivos para o uso da experimentação no ensino de química: a visão de um grupo de licenciandos. In: VII Encontro Nacional de Pesquisa em Educação em Ciências. Florianópolis:nov 2009.

7. Baratieri SM, Basso NRS, Borges RMR, Rocha filho JB. Opinião dos estudantes sobre a experimentação em química no ensino médio. Experiências em Ensino de Ciências. 2008 dez;3(3): 19-31.

8. Galiazzi MC, Rocha JMB, Schmitz LC, Souza ML, Giesta S, Gonçalves FP. Objetivos das atividades experimentais no Ensino Médio: a pesquisa coletiva como formação de professores de ciências. Ciência e Educação, 2001 ago;7(2):249-263, doi: 10.1590/S1516-73132001000200008.

9. Maldaner OA. A Formação Inicial e Continuada de Professores de Química - Professores /Pesquisadores. Ijuí: Universidade Regional do Noroeste do Estado do Rio Grande do Sul; 2003. 424p.

10. Borges AT. Novos rumos para o laboratório escolar de ciências. Caderno Brasileiro de Ensino de Física. 2002 dez;19(1): 291-313.

11. Salvadego WNC, Laburú CE. Uma análise das relações do saber profissional do professor do ensino médio com a atividade experimental no ensino de química. Química Nova na Escola. 2009 ago;31(3): 216-223.

12. Bakhtin M. Estética da criação verbal. São Paulo: Martins fontes, 1997. 512p.

13. Araújo JMA. Química de alimentos: teoria e prática. Viçosa: Imprensa Universitária da Universidade Federal de Viçosa; 1995. 601p.

14. Souza JRDT. Instrumentação para o ensino de Química. Belém: Universidade Federal do Pará; 2011.51p.

15. Freitas Filho JR, Ângelo JHB, Bezerra JDC, Lira CS, Andrade AS, Silva IM, Souza filho JS. Laboratório ambulante de química: instrumento de extensão universitária. Revista Ciência em Extensão.2012 jan./abr.; 8(1): p. 82-97.

16. Bizzo N. Ciências: fácil ou difícil? São Paulo: Ática; 2000. 156p.

17. Krasilchik M. Prática de Ensino de Biologia. São Paulo: Editora da Universidade de São Paulo; 2008. 197p

18. Vieira BDCR, Lorenzoni LS, Gobbo SDA, Brechiani MCM, Souza MHA. "Importância da experimentação em ciências para a construção do conhecimento no ensino fundamental". Enciclopédia Biosfera. 2013 jul;9(16):2276-2285.

19. Melo NS, Silva AB, Jesus MP, Santos LD, Santos KR, Cruz MCP. Abordagem de pigmentos naturais no Ensino de Química através de experimentação. Scientia Plena. 2015.; 11(6): 1-8.

20. Santos AO, Silva RP, Andrade D, Lima JPM. Dificuldades e motivações de aprendizagem em Química de alunos do ensino médio investigadas em ações do (PIBID/UFS/Química). Scientia Plena. 2013.; 9(7): 1-6.

21. Nunes CTS, Lima KS, Santos ML, Silva EL. Cultura, Ciência e Teatro: uma tríade possível para o Ensino de Química. Scientia Plena. 2014.; 10(8): 1-10. 